\title{
Fabrication of High Strength Ti Alloy Compacts by Metal Injection Molding
}

\author{
Yoshinori $\mathrm{ITOH}^{1 *}$ and Hideshi MIURA ${ }^{2}$ \\ ${ }^{1}$ Hamamatsu Technical Support Center Industrial Research Institute of Shizuoka Prefecture, 1-3-3 Shinmiyakoda, Kita-ku, \\ Hamamatsu 431-2103, Japan. \\ ${ }^{2}$ Dept. Mech. Eng., Faculty of Eng., Kyusyu University, 744 Motooka, Nishi-ku, Fukuoka 819-0395, Japan.
}

Received November 30, 2015; Revised January 24, 2016; Accepted January 29, 2016

\begin{abstract}
Ti and its alloys show the excellent characteristics such as low density, high strength, high corrosion resistance and high biocompatibility. Therefore, they have been widely used for various industrial and medical applications. However, they have poor workability, it is difficult to produce the complicate shaped and precise parts. Therefore, the metal injection molding (MIM) is hoped to be a suitable technique for fabricating the complex shaped Ti or its alloy parts with low cost.

In our previous studies, it was found that the strengthening of sintered Ti- $6 \mathrm{Al}-4 \mathrm{~V}$ alloy compacts were available by addition of $\mathrm{Fe}$ or $\mathrm{Cr}$ powders because of their solution strengthening of beta phase.

In this study, the metal injection molding process has been applied to fabricate high strength Ti alloy compacts using mixed elemental powders. The alloy composition was replaced V with Fe, Cr or Mo in Ti-6Al-4V alloy. Eventually, more than $1100 \mathrm{MPa}$ of strength and $8 \%$ of elongation were achieved in Ti-6Al-12.5Mo alloy compact by MIM process.
\end{abstract}

\section{KEY WORDS}

metal injection molding, Ti alloy, mixed powder, strengthening, mechanical property

\section{Introduction}

The metal injection molding (MIM) is hoped to be a suitable technique for fabricating the complex shaped Ti or its alloy parts with low cost. So far, we have applied MIM process to produce various types of Ti alloys using mixed powders such as Ti-6Al-4 $\mathrm{V}^{1)}$, Ti-6Al-2Sn-4Zr-2Mo-0.1 $\mathrm{Si}^{2)}$, Ti-6Al-2Sn-4Zr-6Mo ${ }^{3)}$, Ti-4.3Fe-7.1 $\mathrm{Cr}^{4)}$, and Ti-6Al-7Nb alloys ${ }^{5)}$.

It was found that the strengthening of sintered Ti-6Al-4V alloy compacts were available by addition of fine $\mathrm{Fe}, \mathrm{Cr}$ or Mo powders because of their solution strengthening of beta phase in the previous studies ${ }^{6}$. The tensile strength of the compacts increased with increasing the content of additional elements, but elongation of the compacts decreased with increasing the content of additional elements above 2 mass $\% \mathrm{Fe}, 4$ mass $\% \mathrm{Cr}$ or 4 mass $\%$ Mo. And also, the cost reducing of sintered Ti- $6 \mathrm{Al}-4 \mathrm{~V}$ alloy compacts were available by replacing $\mathrm{V}$ with other beta stabilizing elements such as $\mathrm{Fe}, \mathrm{Cr}$ or $\mathrm{Mo}^{7}$. The tensile strength and elongation of the compacts showed as same as that of sintered Ti-6Al-4V alloy compacts. The content of each replacing elements was the same Molybdenum Equivalence as 4 mass\%V. The Molybdenum Equivalence means phase-stability classifications, shown as Eq. $(1)^{8)}$.

\footnotetext{
* Corresponding author, E-mail: itohy@iri.pref.shizuoka.jp
}

$$
\begin{aligned}
& \text { [Mo]eq } \\
& =[\mathrm{Mo}]+[\mathrm{Ta}] / 5+[\mathrm{Nb}] / 3.6+[\mathrm{W}] / 2.5+[\mathrm{V}] / 1.5+1.25[\mathrm{Cr}] \\
& \\
& \quad+1.25[\mathrm{Ni}]+1.7[\mathrm{Mn}]+1.7[\mathrm{Co}]+2.5[\mathrm{Fe}]:[\operatorname{mass} \%]
\end{aligned}
$$

In this study, the metal injection molding process has been applied to fabricate high strength Ti alloy compacts using mixed elemental powders. The alloy composition was replaced $\mathrm{V}$ with $\mathrm{Fe}, \mathrm{Cr}$ or Mo and increased their content. They are more cost effective elements as compared to $\mathrm{V}$. The effects of $\mathrm{Fe}, \mathrm{Cr}$ or Mo content and sintering conditions on the mechanical properties of the sintered compacts were mainly investigated.

\section{Experimental Procedure}

A gas-atomized pure Ti powder (TILOP-45, Osaka Titanium Technologies Co., Ltd), fine Al powder (Al at 600F, Minalco Ltd.), fine Carbonyl Fe powder (Carbonyl FE MO, Fukuda Metal Foil \& Powder Co., Ltd.), fine Cr powder (ELCR-EL-F4, F. W. Winter Inc. \& Co.) and fine Mo powder (Mo-1KD, Japan New Metals Co., Ltd), were used in this study. The chemical compositions, particle size and scanning electron microscope (SEM) images of those powders are shown in Table 1 and Fig. 1, respectively. To improve the tensile strength of sintered Ti alloy compacts with enough elongation, the Molybdenum Equivalence of each elements were 
Table 1 Chemical compositions and particle size of the powders used in this study.

\begin{tabular}{ccccc}
\hline Powder & $\mathrm{O}(\mathrm{mass} \%)$ & $\mathrm{C}(\mathrm{mass} \%)$ & $\mathrm{Fe}(\mathrm{mass} \%)$ & Partile size $(\mu \mathrm{m})$ \\
\hline Titanium & 0.13 & 0.008 & 0.044 & -45 \\
Alluminum & - & - & - & $5.41^{*}$ \\
Iron & 0.38 & 0.74 & val. & $4.31^{*}$ \\
Chromium & 0.75 & 0.025 & 0.22 & $2.97^{*}$ \\
Molybdenum & 0.20 & - & 0.008 & $1.59^{*}$ \\
\hline
\end{tabular}

* mean particle size

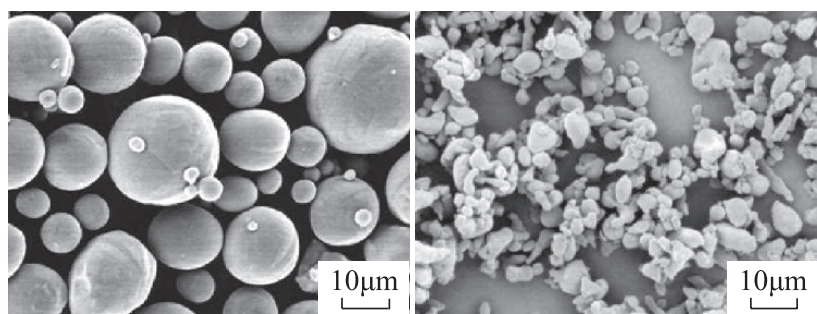

a) Titanium powder

b) Aluminum powder

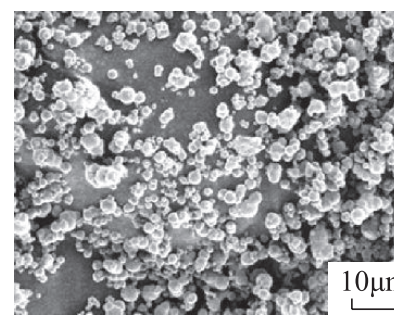

c) Iron powder

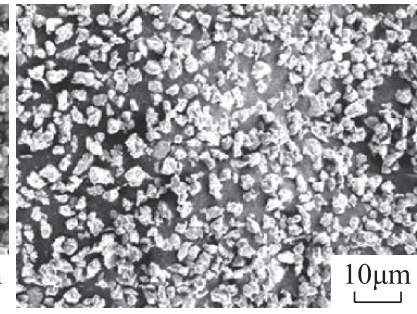

d) Chromium powder

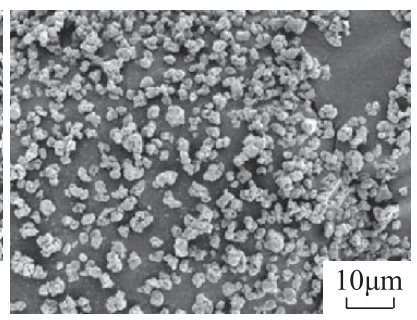

e) Molybdenum powder

Fig. 1 SEM images of a) Titanium, b) Aluminum, c) Iron, d) Chromium and e) Molybdenum powders used in this study.

adjusted to 6.5, in which the content of $\mathrm{Fe}, \mathrm{Cr}$ or Mo was 2.6 mass\%, 5.2 mass $\%$ and 6.5 mass $\%$, respectively. Next, to improve the tensile strength of sintered Ti alloy compacts further more, the content of $\mathrm{Cr}$ were increased up to 7.5 mass $\%$ and 10 mass $\%$ or Mo were increased to 9.4 mass $\%$ and 12.5 mass $\%$, respectively. Those powders were weighed to obtain the chemical compositions of objective Ti alloy, and then were pre-mixed for $3.6 \mathrm{ks}$ by pot mill rotator within argon filled. The powder mixtures were then kneaded with binder (contained polypropylene, polymethyl methacrylate, paraffin wax and stearic acid in a weight ratio of 30:40:29:1) by means of pressure-type kneading machine (Moriyama Co., Ltd., DV1-5GHH-E) at $443 \mathrm{~K}$ for $8.1 \mathrm{ks}$. The powder loading was 65 vol\%. The compounds obtained were crashed and screened from $2 \mathrm{~mm}$ to $8 \mathrm{~mm}$ diameter for a feedstock of injection molding. The feedstock were then injection molded by injection molding machine (Nissei Plastic Industrial Co., Ltd., ST20S2V) into tensile test specimens with a length of $75 \mathrm{~mm}$, a width of $5 \mathrm{~mm}$ and a thickness of $2 \mathrm{~mm}$. After injection molding, the extraction debinding with vaporized solvent, which was conducted at $343 \mathrm{~K}$ for $21.3 \mathrm{ks}$ in n-hexane, was used to partially remove the wax and polymethyl methacrylate. In this treatment, the contamination to sintered compacts by carbon derived from the binder system was reduced. Following this treatment, thermal debinding was performed from room temperature to $703 \mathrm{~K}$ in reduced pressure with argon gas flow, and continuous sintering was performed in high vacuum (in the order of $10^{-2} \mathrm{~Pa}$ under) at various temperatures for $14.4 \mathrm{ks}$, followed by furnace cooling to room temperature in high vacuum (in the order of $10^{-3} \mathrm{~Pa}$ under). The vacuum furnace (Shimadzu Mectem Inc., PVSGgr20/20) used in this study has both heater and vessel made from graphite. Therefore, the compacts were set on an yttria substrate in an inner vessel made from Mo and were surrounded by sponge-like Ti powders to prevent the carburization and oxidation.

The relative densities and tensile properties were measured on as-sintered compacts. The density of sintered compacts were measured by Archimedean method with automatically densimeter (Toyo Seiki Seisaku-Sho, Ltd., DENSIMETER H) for five specimens, then the relative density were estimated from the density of each HIPed Ti alloy compacts after sintering. The tensile test was conducted using a universal testing instrument and non-contact video extensometer (Shimadzu Corp., AG-50kNIS with DVE-201) with an extensometer gauge length of $25 \mathrm{~mm}$ and crosshead speed of $8.33 \times 10^{-5} \mathrm{~m} / \mathrm{s}$ in air at room temperature for three specimens. The tensile strength $(\sigma)$ was corrected by oxygen content $(\mathrm{O})$ and relative density $(\rho)$ with experimental equation (2).

$$
\sigma(\mathrm{MPa})=700 \mathrm{O}(\operatorname{mass} \%)+10 \rho(\%)-315
$$

Because, it was found in previous study ${ }^{9)}$ that the tensile strength 
of sintered Ti-6Al-4V alloy compacts was fairly affected by their oxygen content and relative density. Especially, higher oxygen content of sintered Ti alloy compacts would cause higher tensile strength compared with lower oxygen content of those. Then, to normalize tensile strength of each sintered Ti alloy compacts, this correction was applied at oxygen contest as 0.3 mass $\%$ and relative density as $98 \%$. The oxygen contents were determined by means of Oxygen/Nitrogen analyzer (Horiba, Ltd., EMGA-520) for three specimens. Specimens for microstructural observations were cut from the sintered compacts, and were ground with waterproof emery paper up to \#800, subsequently were polished with $3 \mu \mathrm{m}$ and $1 \mu \mathrm{m}$ of diamond suspensions followed by colloidal silica. Then they were finally etched in Kroll's reagent consist of $3 \mathrm{vol} \%$ of $\mathrm{HF}$ and $6 \mathrm{vol} \%$ of $\mathrm{HNO}_{3}$ and $91 \mathrm{vol} \%$ of water for $20 \mathrm{~s}$. Microstructural observations of the specimens were conducted using an optical microscope (Olympus Corp., GX71 + DP71). To determine the distribution of each element in the sintered compacts, characteristics X-ray images were taken by means of electron probe micro analyzer with wavelength dispersive analyzer (Shimadzu Corp., EPMA-1720). Fracture surface of the specimens after tensile test were also observed by using scanning electron microscope (JEOL Ltd., JSM-6300F).

\section{Results and Discussions}

The tensile strength and elongation of Ti-6Al-X alloy compacts sintered at various temperatures for replacing $\mathrm{V}$ with $\mathrm{Fe}, \mathrm{Cr}$ or $\mathrm{Mo}$ and increasing their content up to expected good elongation are shown in Figs. 2 and 3. The tensile strength of sintered compacts is significantly improved about $100 \mathrm{MPa}$ by replacing $\mathrm{V}$ with $\mathrm{Fe}$, $\mathrm{Cr}$ or Mo and increasing their content, and that is nearly constant at sintering temperature above $1423 \mathrm{~K}$. The elongation of the sintered compacts replaced $\mathrm{Cr}$ or Mo is improved about $3 \%$ at sintering temperature above $1423 \mathrm{~K}$, but they are slightly reduced in high sintering temperature. In contrast, the elongation of the sintered

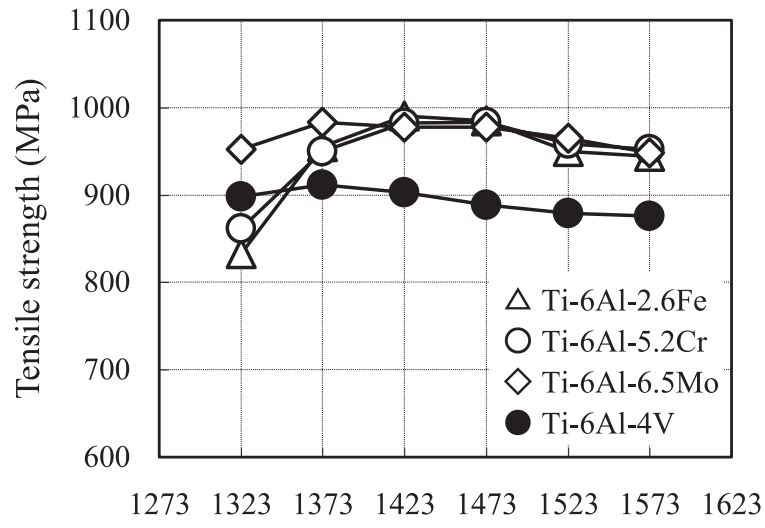

Sintering temperature $(\mathrm{K})$

Fig. 2 Effect of sintering temperature on the tensile strength of Ti alloy compacts replaced $\mathrm{V}$ with $\mathrm{Fe}, \mathrm{Cr}$ or Mo and increased their content in Ti-6Al-4V alloy. compacts replaced $\mathrm{Fe}$ is increasing with increasing sintering temperature, but the elongation was reached to only $8 \%$ at $1423 \mathrm{~K}$. From these results, $\mathrm{Cr}$ and Mo are expected to more strengthen the $\mathrm{Ti}$ alloys with enough ductility. Then, the content of $\mathrm{Cr}$ or Mo was further increased.

The effect of sintering temperature and $\mathrm{Cr}$ or Mo content on the relative density of Ti alloy compacts in Ti-6Al-X alloy are shown in Figs. 4 and 5. The relative density of the compacts increase with increasing sintering temperature and reached up to $98 \%$ at $1473 \mathrm{~K}$ by $\mathrm{Cr}$, and $99 \%$ at $1473 \mathrm{~K}$ by Mo. The relative density of the compacts replaced Mo is about $1 \%$ higher than that of the compacts replaced $\mathrm{Cr}$.

The effect of sintering temperature and $\mathrm{Cr}$ or Mo content on the tensile strength of Ti alloy compacts are shown in Figs. 6 and 7. The tensile strength is significantly improved by increasing $\mathrm{Cr}$ or Mo content. The tensile strength of sintered compacts is improved to around $80 \mathrm{MPa}, 160 \mathrm{MPa}$ and $240 \mathrm{MPa}$ by increasing $\mathrm{Cr}$ or Mo content, and the maximum strength was $1140 \mathrm{MPa}$ in Ti-6Al$12.5 \mathrm{Mo}$ alloy. Moreover, the tensile strength of these Ti alloy

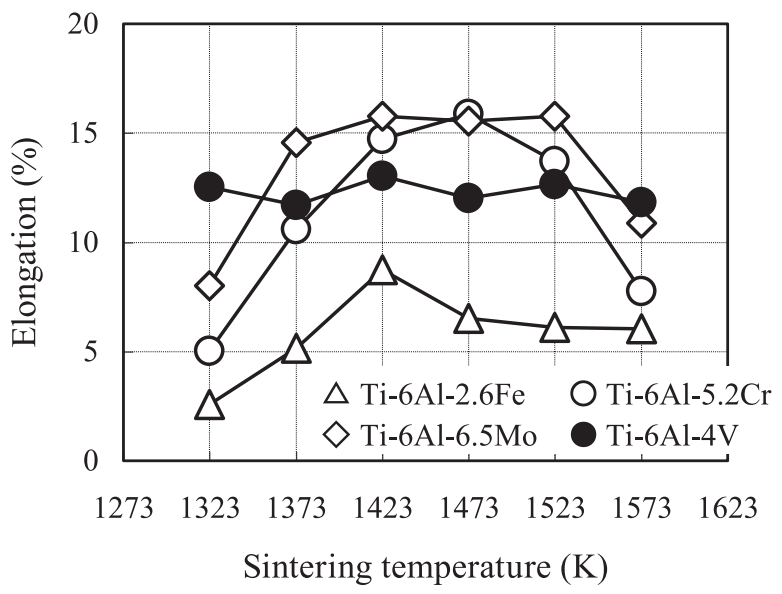

Fig. 3 Effect of sintering temperature on the elongation of Ti alloy compacts replaced $\mathrm{V}$ with $\mathrm{Fe}, \mathrm{Cr}$ or $\mathrm{Mo}$ and increased their content in Ti-6Al-4V alloy.

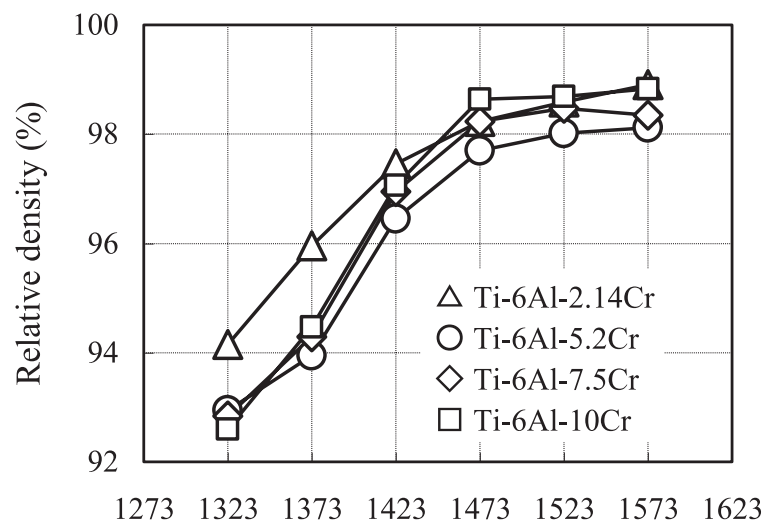

Sintering temperature $(\mathrm{K})$

Fig. 4 Effect of sintering temperature and $\mathrm{Cr}$ content on the relative density of Ti alloy compacts replaced $\mathrm{V}$ with $\mathrm{Cr}$ in Ti-6Al-4V alloy 


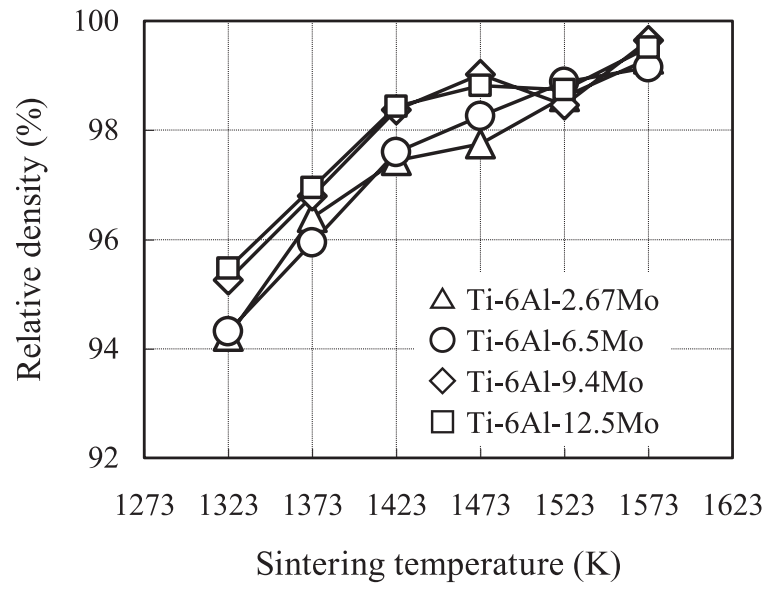

Fig. 5 Effect of sintering temperature and Mo content on the relative density of Ti alloy compacts replaced $\mathrm{V}$ with Mo in Ti-6Al-4V alloy.

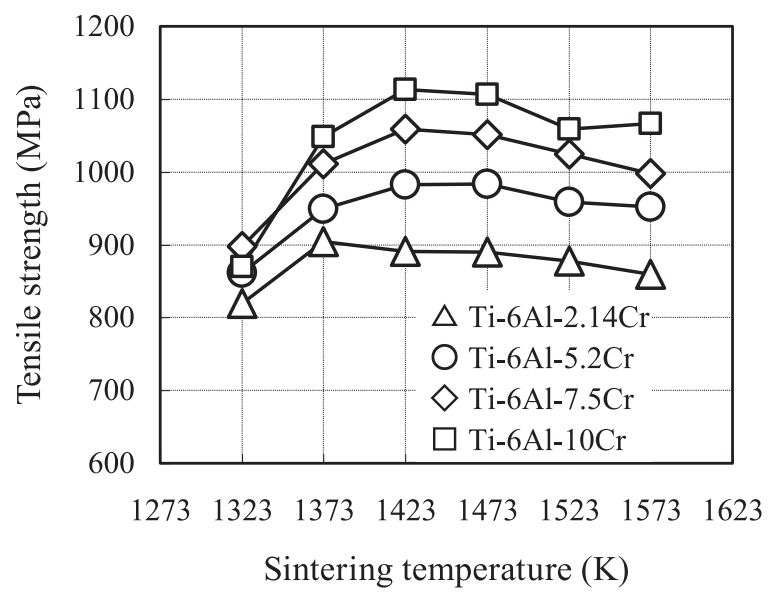

Fig. 6 Effect of sintering temperature and $\mathrm{Cr}$ content on the tensile strength of Ti alloy compacts replaced $\mathrm{V}$ with $\mathrm{Cr}$ in Ti-6Al-4V alloy.

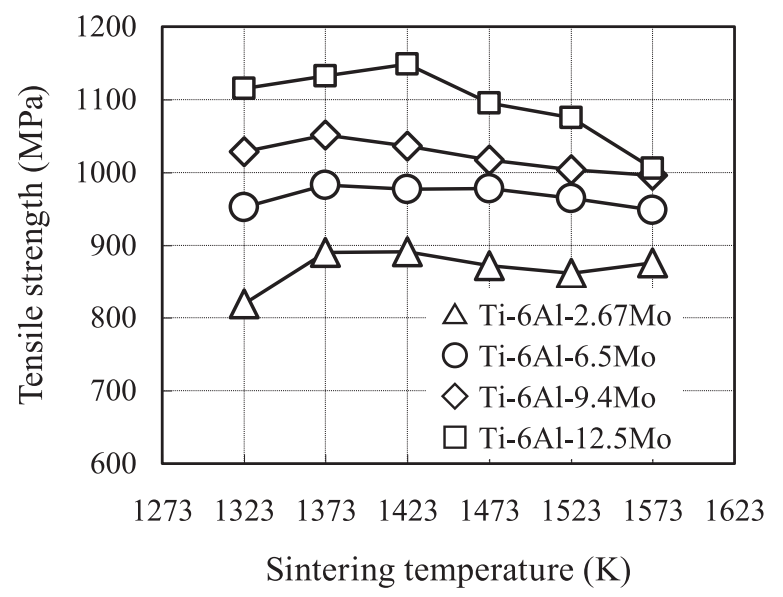

Fig. 7 Effect of sintering temperature and Mo content on the tensile strength of Ti alloy compacts replaced $\mathrm{V}$ with Mo in Ti-6Al-4V alloy.

compacts is slightly decreased with increasing sintering temperature above $1473 \mathrm{~K}$.

The effect of sintering temperature and $\mathrm{Cr}$ or Mo content on the elongation of Ti alloy compacts are shown in Figs. 8 and 9. The

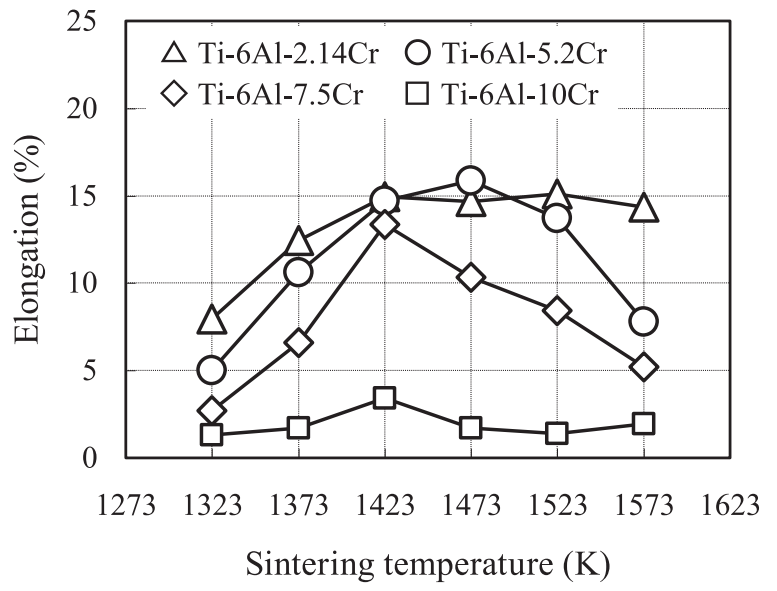

Fig. 8 Effect of sintering temperature and $\mathrm{Cr}$ content on the elongation of Ti alloy compacts replaced V with $\mathrm{Cr}$ in Ti-6Al-4V alloy.

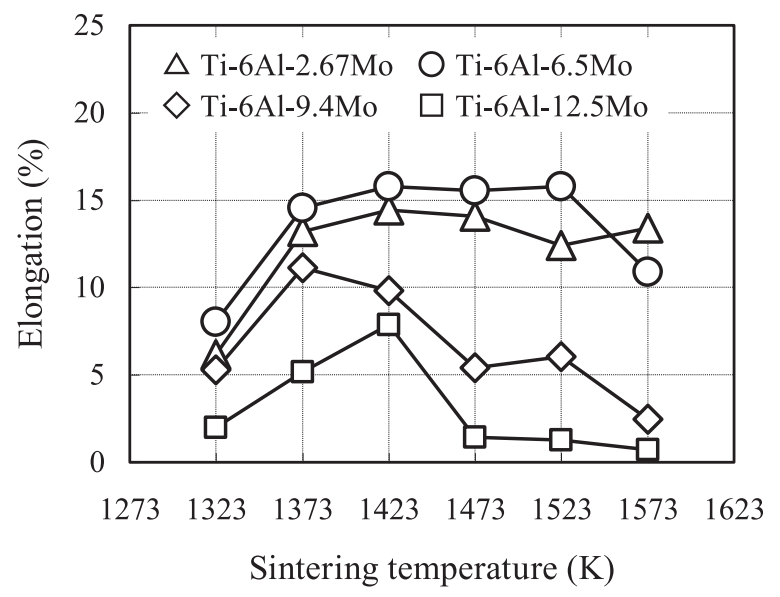

Fig. 9 Effect of sintering temperature and Mo content on the elongation of Ti alloy compacts replaced V with Mo in Ti-6Al-4V alloy.

elongation of sintered compacts is decreased with increasing $\mathrm{Cr}$ or Mo content, and decrease with increasing sintering temperature above $1473 \mathrm{~K}$. The elongation of sintered Ti-6Al-10Cr alloy compacts was only under $4 \%$. The elongation of sintered Ti-6Al$12.5 \mathrm{Mo}$ alloy compacts was below $10 \%$, it was barely reached up to $8 \%$ at $1423 \mathrm{~K}$.

The effect of sintering temperature and $\mathrm{Cr}$ or Mo content on the oxygen content of Ti alloy compacts are shown in Figs. 10 and 11. The oxygen content of sintered compacts is slightly increased with increasing sintering temperature and increasing $\mathrm{Cr}$ or Mo content. These values are considered sufficiently low level such that they do not have a detrimental effect on the elongation of sintered compacts).

Fig. 12 shows the effect of $\mathrm{Cr}$ or Mo content on the microstructures of Ti alloy compacts sintered at $1423 \mathrm{~K}$ or $1473 \mathrm{~K}$. The microstructures of all sintered compacts consist of the acicular alpha phase and intergranular beta phase. The acicular alpha phase become fine with increasing $\mathrm{Cr}$ or Mo content and the acicular alpha was finer for the compacts replaced with Mo as compared with that of replaced Cr. These lamellar like structure caused by transformation from 


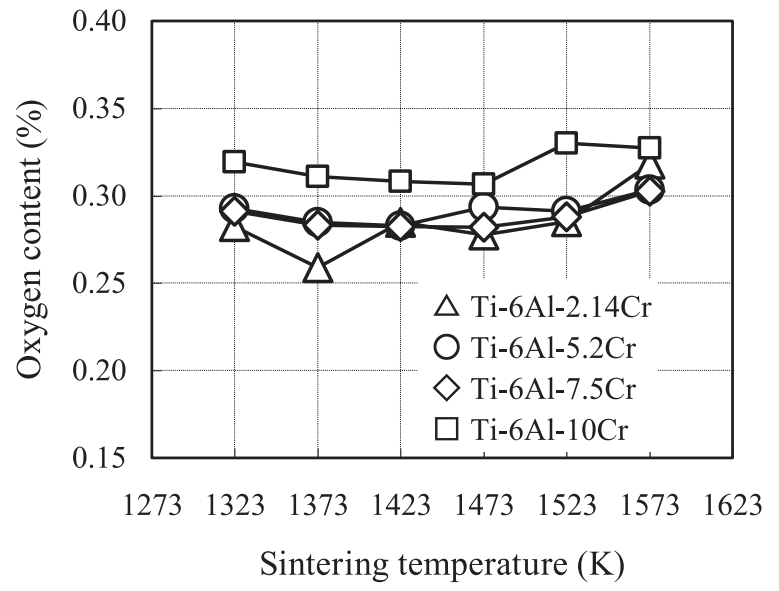

Fig. 10 Effect of sintering temperature and $\mathrm{Cr}$ content on the oxygen content of Ti alloy compacts replaced $\mathrm{V}$ with $\mathrm{Cr}$ in Ti-6Al-4V alloy.

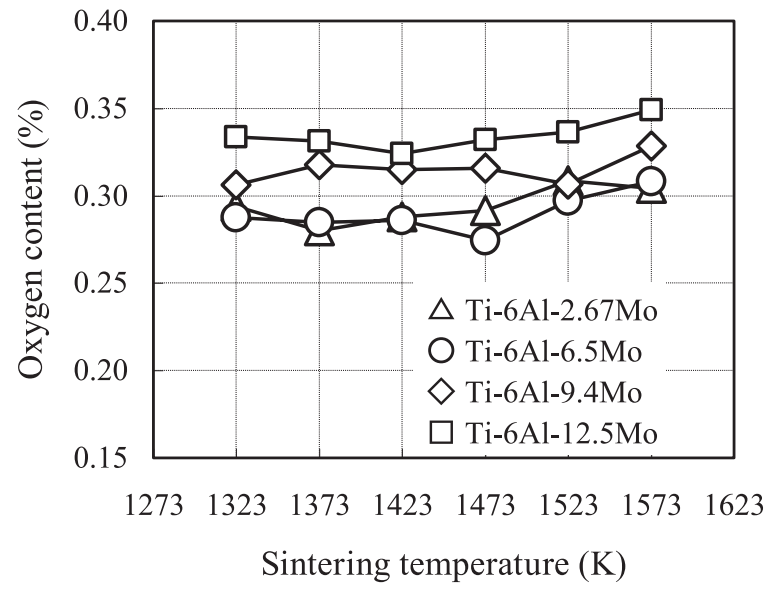

Fig. 11 Effect of sintering temperature and Mo content on the oxygen content of Ti alloy compacts replaced $\mathrm{V}$ with Mo in Ti-6Al-4V alloy.

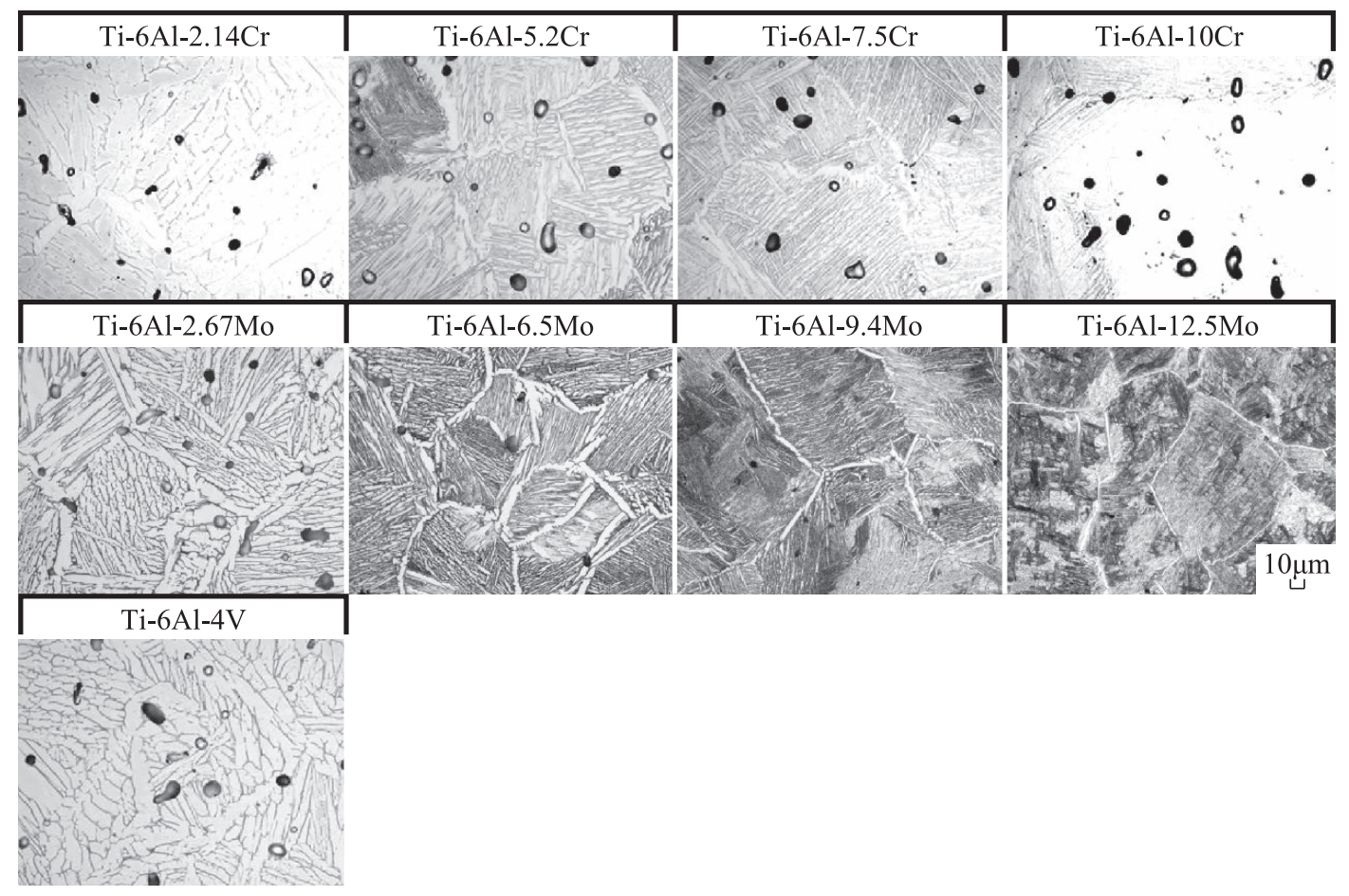

Fig. 12 Effect of $\mathrm{Cr}$ or Mo content on the microstructures of Ti alloy compacts replaced V with them in Ti-6Al-4V alloy and sintered at $1423 \mathrm{~K}$ or $1473 \mathrm{~K}$.

equiaxed beta grains during cooling, and then the grain size of prior beta was nearly the same in all the sintered compacts (approximately $50 \mathrm{um}$ ). From these observations, it is considered that solution strengthening and the microstructural modification has effected on the strengthening of the sintered compacts.

Fig. 13 shows $\mathrm{Cr}-\mathrm{K} \alpha$ or Mo-L $\alpha$ characteristic X-ray images of $\mathrm{Ti}$ alloy compacts sintered at $1423 \mathrm{~K}$ or $1473 \mathrm{~K}$. $\mathrm{Cr}$ and Mo as beta stabilizing elements are concentrated at the beta phase with a dark line as shown in Fig. 12, and also they are sufficiently homogenized for all the sintered compacts. This seems to be due to the enhancement of elemental diffusion by additional small particles $\mathrm{Cr}$ and Mo powders. The dark fine linear or coarse line area indicate acicular alpha phase or alpha phase at prior beta grain boundaries, those area of sintered Ti-6Al-10Cr alloy compacts is slightly inhomogeneous compared with sintered Ti-6Al-12.5Mo alloy compact.

Fig. 14 shows SEM images of fracture surface of Ti alloy compacts sintered at $1423 \mathrm{~K}$ or $1473 \mathrm{~K}$. The fracture surface of sintered Ti alloy compacts except Ti-6Al-10Cr and Ti-6Al-12.5Mo alloys shows the ductile fracture. The fracture surface of sintered Ti-6Al-12.5Mo alloy compact shows the ductile fracture area and brittle fracture area, then their elongation was barely reached up to $8 \%$. The fracture surface of sintered Ti-6Al-10Cr alloy compact shows only the brittle fracture caused from lamellar like structure or prior beta grain boundary. 


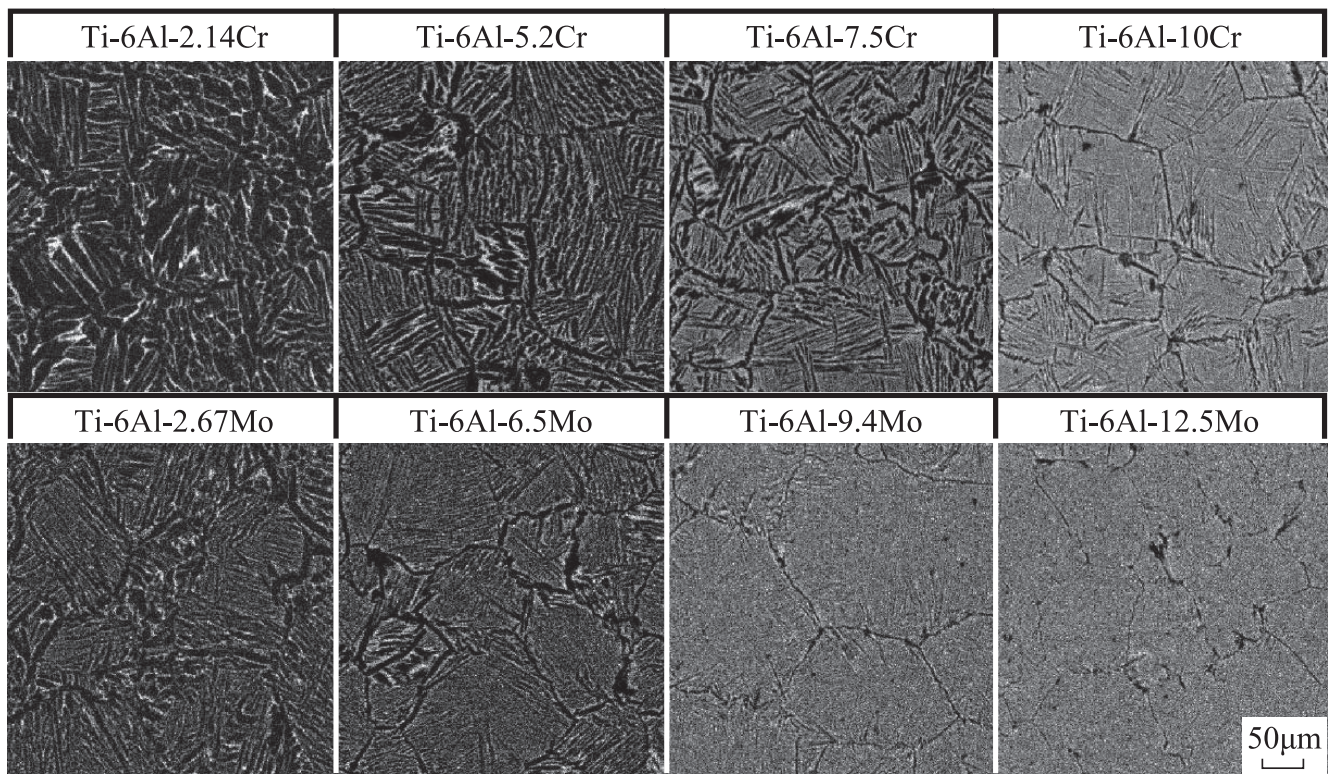

Fig. $13 \mathrm{Cr}-\mathrm{K} \alpha$ or Mo-L $\alpha$ characteristic X-ray images of Ti alloy compacts replaced $\mathrm{V}$ with them increased their content in Ti-6Al-4V alloy and sintered at $1423 \mathrm{~K}$ or $1473 \mathrm{~K}$.

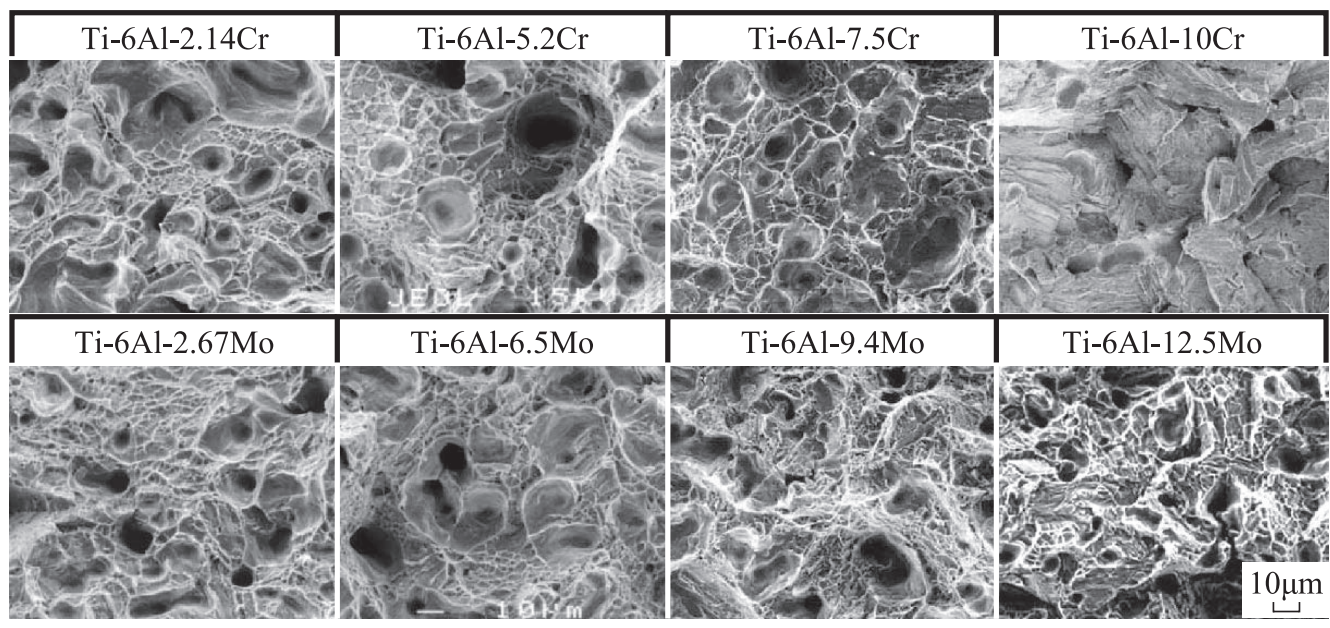

Fig. 14 SEM images of fracture surface of Ti alloy compacts replaced V with $\mathrm{Cr}$ or Mo and increased their content in Ti-6Al-4V alloy and sintered at $1423 \mathrm{~K}$ or $1473 \mathrm{~K}$.

\section{Conclusion}

The metal injection molding process has been applied to fabricate high strength Ti alloy compacts by replacing $\mathrm{V}$ with $\mathrm{Fe}, \mathrm{Cr}$ or Mo and increasing the content of those third elements in Ti-6Al-X alloy compacts.

In the 1 st study, the content of each replaced element were adjusted Molybdenum Equivalence around 6.5. In this content, the elongation of sintered these Ti alloy compacts was expected over $10 \%$ from the result of previous studies. The tensile strength of the sintered compacts replacing Fe was improved, but their elongation was reduced to around $5 \%$. In contrast, the tensile strength of the sintered compacts replacing $\mathrm{Cr}$ or Mo was improved with keeping good elongation, around $15 \%$.

In the 2 nd study, to further improve the tensile strength, the content of $\mathrm{Cr}$ or Mo was increased. The tensile strength of sintered
Ti alloy compacts were increased with increasing the content of $\mathrm{Cr}$ or Mo, but elongation of those was decreased.

Eventually, more than $1100 \mathrm{MPa}$ of strength and $8 \%$ of elongation were achieved in Ti-6Al-12.5Mo alloy compact by MIM process.

\section{References}

1) Y. Itoh, T. Harikou, K. Sato, H. Miura: "Improvement of Ductility for Injection Moulded Ti-6Al-4V Alloy", Proceedings of 2004 Powder Metallurgy World Congress, H. Danninger and R. Ratzi ed., Vienna, European Powder Metallurgy Association, 4 (2004) 445-450.

2) Y. Itoh, T. Harikou, K. Sato, H. Miura: "Fabrication of Near- $\alpha$ Titanium Alloy by Metal Injection Molding”, J. Jpn. Soc. Powder Powder Metallurgy, 52 (2005) 43-48.

3) Y. Itoh, T. Uematsu, K. Sato, H. Miura, M. Niinomi: "Fabrication 
of High Strength $\alpha+\beta$ type Titanium Alloy Compacts by Metal Injection Molding”, J. Jpn. Soc. Powder Powder Metallurgy, 55 (2008) 720-725.

4) Y. Itoh, T. Uematsu, K. Sato, H. Miura, M. Niinomi, M. Ikeda: "Sintering Behavior and Mechanical Properties of Injection Molded Ti-4.3Fe-7.1Cr Alloys", J. Jpn. Soc. Powder Powder Metallurgy, 53 (2006) 821-826.

5) Y. Itoh, H. Miura, T. Uematsu, K. Sato, M. Niinomi, T. Ozawa: "Effect of Mixed Powders on the Properties of Ti6Al-7Nb Alloy by Metal Injection Molding”, Ti-2007 Science and Technology, 2 (2007) 1185-1188.

6) Y. Itoh, H. Miura, T. Uematsu, T. Osada, K. Sato: "Effect of Fe or Cr Addition on the Strengthening Ti-6Al-4V Alloy by
Metal Injection Molding", J. Solid Mechanics and Materials Engineering, 3 (2009) 921-930.

7) Y. Itoh, T. Uematsu, H. Miura, M. Niinomi: "Development of High Performance Injection Molded Titanium Alloys Equivalent to Ti-6Al-4V using Mixed Elemental Powders", Abstracts of Spring Meeting JSPM, (2011) 115.

8) R. Boyer, G. Welsch, E. W. Collings: Materials Properties Handbook: Titanium Alloys, Third printing, ASM International, (1994) 10.

9) Y. Itoh, T. Uematsu, K. Sato, H. Miura: "Effect of Oxygen Content and Relative Density on the Tensile Properties of Injection Molded Ti-6Al-4V Alloy", J. Jpn. Soc. Powder Powder Metallurgy, 56 (2009) 259-263. 